\title{
SOBRE EL EXCEPCIONAL DERECHO DEL ACREEDOR AL VALOR DE LA COSA O HECHO OBJETO DE LA PRESTACIÓN ¿REPARACIÓN DE UN DAÑO INTRÍNSECOO CUMPLIMIENTO POR EQUIVALENCIA? BASES PARA UNA REFUTACIÓN DEL REALISMO INTEGRADOR
}

\author{
ON THE EXCEPTIONAL RIGHT OF THE CREDITOR TO THE \\ VALUE OF THE OBJECT OF THE DEBT: COMPENSATION OF \\ AN INTRINSIC DAMAGE OR MONETARY AMOUNT IN LIEU OF \\ SPECIFIC PERFORMANCE? \\ BASES FOR A REFUTATION OF INTEGRATIVE REALISM
}

SEBASTIÁN CAMPOS MICIN *

\section{RESUMEN}

El objetivo de este estudio es intentar una refutación de los argumentos que últimamente ha esgrimido parte de la doctrina nacional para sustentar la integración de la aestimatio rei en la indemnización de perjuicios. Además de revisar el estado de la discusión y explicar el rol decidor que al respecto desempeña el artículo 1521 del Código Civil, se ponen en cuestión la pretendida función resarcitoria del cumplimiento por equivalencia, la afirmación de que la destrucción de la especie o cuerpo cierto por causa imputable al deudor comporta un daño intrínseco y la supuesta inconveniencia de la existencia de un régimen diferenciado.

Palabras clave: Cumplimiento por equivalencia, Indemnización de perjuicios, Perpetuatio obligationis, Aestimatio rei, Daños intrínsecos.

\footnotetext{
* Licenciado en Ciencias Sociales y Jurídicas, Universidad de Chile. Magíster en Derecho con mención en Derecho Privado, Universidad de Chile. Máster en Economía y Derecho del Consumo, Universidad de Castilla-La Mancha. Doctorando en Derecho, Universidad de Chile. Profesor instructor, Universidad de Chile, Santiago, Chile. Correo electrónico: scampos@derecho.uchile.cl. ORCID: https://orcid. org/0000-0002-3236-8630.
}

Trabajo recibido el 11 de agosto de 2020 y aceptado para su publicación el 14 de junio de 2021 . 


\section{ABSTRACT}

The purpose of this paper is to attempt a refutation of the arguments that have been said lately by part of the national doctrine to support the integration of the aestimatio rei in the damages compensation. Also, in addition to reviewing the state of the discussion and explaining the decision-making role that article 1521 of the Civil Code plays in this regard, it is questioned the compensatory function of monetary amount in lieu of specific performance, the claim that the destruction of the item by cause attributable to the debtor entails intrinsic damage and the so-called inconvenience of the existence of a differentiated regime.

Keywords: Monetary amount in lieu of specific performance, Due compensation, Perpetuatio obligationis, Aestimatio rei, Intrinsic damages.

\section{INTRODUCCIÓN}

En Chile, según buena parte de la doctrina y la jurisprudencia, la indemnización de perjuicios por incumplimiento contractual implica un cumplimiento por equivalencia, pues supone el pago de una suma de dinero equivalente al beneficio pecuniario que habría reportado al acreedor el cumplimiento fiel y oportuno de la obligación. ${ }^{1}$ Desde esta perspectiva -

\footnotetext{
${ }^{1}$ Alessandri, Arturo, Teoría de las obligaciones, Editorial Jurídica Ediar-Conosur Ltda, Santiago, 1988, pp. 74 y 75; FueYo, Fernando, Cumplimiento e incumplimiento de las obligaciones, Editorial Jurídica, Santiago, 2004, $3^{a}$ edición actualizada por el Profesor Gonzalo Figueroa Yáñez, pp. 341 y 342, ABeLIUK, René, Las obligaciones, Thomson Reuters, Santiago, 2014, $6^{\text {a }}$ edición actualizada, T. II, pp. 943 y 944; Gatica, Sergio, Aspectos de la indemnización de perjuicios por incumplimiento de contrato, Editorial Jurídica, Santiago, 1958, pp. 10 y 11; Claro, Luis, Explicaciones de derecho civil chileno y comparado, Editorial Jurídica, Santiago, 2013, T. XI, p. 637; MezA, Ramón, De las Obligaciones, Editorial Jurídica, Santiago, 2007, $10^{a}$ edición actualizada, p. 120; Ramos, René, De las Obligaciones, LegalPublishing Chile, Santiago, 2008, $3^{\mathrm{a}}$ edición revisada y corregida, p. 239; VIAL, Víctor, Manual del Derecho de las Obligaciones en el Código Civil chileno, Editorial Biblioteca Americana (Universidad Andrés Bello), Santiago, 2003, p. 206; Rodríguez, Pablo, Responsabilidad contractual, Editorial Jurídica, Santiago, 2003, p. 231; Ruz, Gonzalo, Explicaciones de Derecho Civil. Obligaciones, Legal Publishing Chile, Santiago, 2011, pp. 276 y 277; AlCALDE, Enrique, La responsabilidad contractual. Causa y efectos de los contratos y sus obligaciones, Ediciones UC, Santiago, 2018, p. 472. En la jurisprudencia, se pueden referir, entre otras sentencias: Corte Suprema, 17 de abril de 2008, Rol № 297-2007; Corte Suprema, 30 de marzo de 2009, Rol No 6779-2007; Corte Suprema, 7 de septiembre de 2010, Rol $\mathrm{N}^{\circ}$ 1089-2009; Corte Suprema, 25 de julio de 2011, Rol N 3929-2010; Corte Suprema, 2 de octubre de 2013, Rol N 8607-2012; Corte Suprema, 14 de noviembre de 2016, Rol № 5746-2016; Corte Suprema, 30 de enero de 2020, Rol No 8596-2018.
} 
especialmente operativa para las obligaciones no dinerarias-, la obligación de indemnizar sería la misma que dejó de cumplirse, pero con un nuevo objeto: una suma de dinero. En esta línea, las garantías que aseguran la ejecución de la prestación asegurarían también el pago de la indemnización. Asimismo, los eventuales vicios de nulidad de que adolezca el respectivo contrato no solo podrían extinguir el deber de ejecutar la prestación (ex artículo 1567 $\mathrm{N}^{\circ} 8$ del Código Civil), sino también el deber de pagar la indemnización correspondiente. Esta aproximación, que presupone una subrogación real del objeto de la prestación, encontraría sustento en los artículos 1672 y 1555 inciso primero del Código Civil. ${ }^{2}$ A mayor abundamiento, la indemnización tendería a la satisfacción del interés positivo del acreedor, colocándolo en una posición análoga a la que habría alcanzado de haberse ejecutado el contrato oportuna y fielmente. ${ }^{3}$ En consecuencia, la indemnización tendría un alcance amplio, constituyendo una estimación en dinero del interés del acreedor en el cumplimiento (id quod interest). ${ }^{4}$

No obstante, si bien es relativamente pacífico que la función de la indemnización es dejar al acreedor en una posición análoga a la que habría alcanzado con el cumplimiento, ${ }^{5}$ la noción de cumplimiento por

\footnotetext{
${ }^{2}$ Haciendo esta puntualización, Alessandri, cit. (n. 1), p. 76; Gatica, cit. (n. 1), p. 20; Claro, cit. (n. 1), p. 637; FueYo, cit. (n. 1), p. 343; AbeliuK, cit. (n. 1), pp. 946-948; RodríGUEZ, cit. (n. 1), pp. 10, 11 y 231; Ruz, cit. (n. 1), pp. 278 y 279; AlCALde, cit. (n. 1) p. 472. Técnicamente, aunque no todos los autores citados lo señalen con completa claridad, la subrogación se produciría a propósito de la indemnización compensatoria, máxime si se considera que la moratoria, además de ser exigible junto con el cumplimiento específico, solo tiene por finalidad reparar los perjuicios causados por el retardo. Bahamondes, Claudia, El cumplimiento específico de los contratos, Der Ediciones, Santiago, 2018, pp. 170 y 171.

${ }^{3}$ Así lo hacen notar De La MAZA, Íñigo; VidAL, Álvaro, Cuestiones de Derecho de Contratos. Formación, incumplimiento y remedios. Doctrina y jurisprudencia, Thomson Reuters, Santiago, 2018, pp. 610-614; CÁrdenas, Hugo y Reveco, Ricardo, Remedios contractuales. Cláusulas, acciones y otros mecanismos de tutela del crédito, Thomson Reuters, Santiago, 2018, p. 378.

${ }^{4}$ Con la expresión id quod interest hacemos alusión al interés jurídicamente protegido por el contrato, esto es, al interés que tiene el acreedor en el cumplimiento de la obligación y que efectivamente resulta amparado por el contrato. IHERING, Rudolf, "Del interés en los contratos y de la supuesta necesidad del valor patrimonial de las prestaciones obligatorias", en: IHERING, Rudolf, Tres Estudios Jurídicos, Editorial Atalaya, Buenos Aires, 1947, traducción de Adolfo González Posada, p. 43. La noción, no obstante, en ocasiones es utilizada para hacer alusión específica a los daños que van más allá del valor de la prestación (así, por ejemplo, en Morales, Antonio, "Evolución del concepto de obligación en derecho español", en: MoRales, Antonio, La modernización del derecho de obligaciones, ThomsonCivitas, Cizur Menor, 2006, pp. 47 y 48). Para una tipología de los intereses del acreedor, Llamas, Eugenio, "Tipología de los intereses del acreedor e instrumentos para su satisfacción", Revista de la Asociación Española de Abogados Especializados en Responsabilidad Civil y Seguro, 2013, No 45, pp. 9-24.

${ }^{5}$ De la Maza y Vidal, cit. (n. 3), p. 614; López, Patricia, "La autonomía de la indemnización de
} 
equivalencia puede inducir a equívocos. En efecto, esta noción en ocasiones se concibe como una suma de dinero equivalente al valor intrínseco de la cosa o hecho que es objeto de la prestación, ${ }^{6}$ de modo que, si se acepta que el id quod interest puede ir más allá de dicho valor, no debería asimilarse la indemnización a un mero cumplimiento por equivalencia $-\mathrm{o}$, al menos, debería precisarse que este no consiste en la mera estimación pecuniaria del objeto de la prestación-.

En rigor, tal como sostiene BARAONA, "el problema del id quod interest ha supuesto una gran dificultad para los autores en todos los tiempos, pues siempre ha sido difícil determinar, frente a una falta de cumplimiento, cuáles son los perjuicios que se han causado al acreedor. La evolución de las normas desde el Derecho romano clásico hasta hoy es interesantísima, y puede concluirse que como mínimo son dos los conceptos a tener presente: el valor de la prestación en sí considerado, que en el Código Civil muchas veces se representa con el precio de la cosa, y los perjuicios propiamente tales". ${ }^{7}$

En este orden de ideas, asumiendo que el cumplimiento por equivalencia se refiere a una suma de dinero equivalente al valor intrínseco del objeto de la prestación, una cuestión que está siendo discutida por doctrina nacional contemporánea es si tal estimación pecuniaria no es más que una partida de la indemnización de perjuicios, o si, en cambio, constituye una modalidad de cumplimiento específico procedente en ciertos casos reconocidos por el derecho sustantivo.

Pese a existir diversas disposiciones en el Código Civil que avalarían la última tesis, la mayoría de los autores nacionales, en línea con cierta

daños por incumplimiento de un contrato bilateral en el Código Civil chileno", Legal Publishing Chile, Santiago, 2015, p. 173; AlCalde, cit. (n. 1), pp. 472 y 474 . Poniendo en cuestión el punto, CÁrdenas y Reveco, cit. (n. 3), pp. 378-382. Cabe añadir que algunos autores asignan también una función sancionatoria a la indemnización: AlESSANDRI, cit. (n. 1), p. 75; RAmos, cit. (n. 1), pp. 239 y 240; AbeliuK, cit. (n. 1), p. 945; Ruz, cit. (n. 1), p. 276; AlCAlde, cit. (n. 1), pp. 466-472.

${ }^{6}$ Así lo sugiere AlESSANDRI a propósito del artículo 1672, regla que, según él, cuando habla de precio, se estaría refiriendo a la indemnización compensatoria; ALESSANDRI, cit. (n. 1), p. 78. En el mismo sentido, ABELIUK, refiriendo como ejemplo un caso en que un deudor destruye culpablemente el vehículo que debe dar, señala que "el precio de este es la indemnización compensatoria", ABELIUK, cit. (n. 1), p. 947.

${ }^{7}$ BARAONA, Jorge, "Responsabilidad contractual y factores de imputación de daños: apuntes para una relectura en clave objetiva", Revista Chilena de Derecho, 1997, vol. 24, № 1, p. 156. 
doctrina española, ${ }^{8}$ aboga por un realismo integrador, ${ }^{9}$ concluyendo que el cumplimiento por equivalencia no es más que una partida indemnizatoria. ${ }^{10}$ La discusión no es bizantina, pues, como veremos, la asunción de una u otra tesis tiene diversas e intrincadas implicancias.

Así las cosas, en este artículo nos proponemos revisar y poner en cuestión los argumentos que niegan la distinción entre cumplimiento por equivalencia e indemnización de perjuicios. Para estos efectos, partiremos por presentar las bases normativas y las consecuencias de la tesis que aboga

\footnotetext{
${ }^{8}$ Pantaleón, Fernando, "Las nuevas bases de la responsabilidad contractual", Anuario de Derecho Civil, 1993, 4, XLVI, pp. 1052-1055; Morales, cit. (n. 4), pp. 47-51; Morales, Antonio, "Pretensión de cumplimiento y pretensión indemnizatoria", en: MoRALES, Antonio, La modernización del derecho de obligaciones, Thomson-Civitas, Cizur Menor, 2006, p. 91; GóMEZ, Fernando, "El incumplimiento contractual en derecho español", Revista para el Análisis del Derecho, 2007, № 3, p. 15; DíEz-PicAzo, Luis, Fundamentos del derecho civil patrimonial, volumen II, Las relaciones obligatorias, CivitasThomson Reuters, Pamplona, 2008, 6a edición, pp. 780 y 781; SÁnchez, Juan David, "El cumplimiento por equivalente: ¿un modo de evitar los requisitos imprescindibles en toda pretensión indemnizatoria?", Anuario de Derecho Civil, 2010, N 63, 4, pp. 1740, 1741 y 1747.

En contra, entre otros: Puig, José, "Comentario del traductor a la obra", en: Fuller, Lon y Perdue, William, Indemnización de los daños contractuales y protección de la confianza, Bosch, Barcelona, 1957, pp. 151, 158, 161, 162 y 205; Jordano, Francisco, La responsabilidad contractual, Civitas, Madrid, 1987, p. 238, nota al pie $\mathrm{N}^{\circ} 266$; Llamas, Eduardo, Cumplimiento por equivalente $y$ resarcimiento del daño al acreedor, Editorial Trivium, Madrid, 1999, p. 315.

${ }^{9}$ Así designa VATtier Fuenzalida a la postura doctrinal en cuya virtud el equivalente pecuniario se mira como una partida de la indemnización de daños, en: VATTIER, Carlos, "Notas sobre el incumplimiento y la responsabilidad contractual", Revista electrónica del Departamento de Derecho de la Universidad de La Rioja, 2005, No. 3, p. 59.

${ }^{10}$ VIDAL, Álvaro, “Cumplimiento en equivalencia o indemnización de daños?”, en: Corral, Hernán y Manterola, Pablo (editores), Estudios de Derecho Civil XII, Ponencias presentadas en las XIX jornadas nacionales de Derecho Civil, 6 y 7 de octubre de 2016, Maitencillo, Thomson Reuters, Santiago, 2017, pp. 495 y 496; De la Maza y Vidal, cit. (n. 3), pp. 371-374; Pizarro, Carlos, "La responsabilidad contractual en el derecho chileno: función y autonomía", en: PIZARRo, Carlos; VIDAL, Álvaro, Incumplimiento contractual, resolución e indemnización de daños, Bogotá, Universidad del Rosario, Bogotá, 2010, pp. 299-308; BAHAMONDES, cit. (n. 2), pp. 170-177; BAHAMONDES, Claudia, "El procedimiento de ejecución forzada de las obligaciones y la aestimatio rei", en: VIDAL, Álvaro (Dir.); Severín, Gonzalo (Ed.), Estudios de Derecho de Contratos. En homenaje a Antonio Manuel Morales Moreno, Thomson Reuters, Santiago, 2018a, pp. 611-614; LóPEz, cit (n. 5), pp. 167-173; CÁrdenas y Reveco, cit. (n. 3), pp. 295-298 y 304; Alcalde, Jaime, "La reaparición de la cosa perdida y la facultad del acreedor para reclamarla", Revista de Derecho P. Universidad Católica de Valparaíso, 2012, XXXVIII, pp. 57 y 70. En contra, BARAONA, cit. (n. 7), pp. 159-165; PeÑaIliLlo, Daniel, "Responsabilidad contractual objetiva", en: Pizarro, Carlos (coord.), Estudios de Derecho Civil $I V$, Legal Publishing, Santiago, 2009, pp. 335-338; Bustamante, Luis, "Autonomía del equivalente pecuniario o su integración dentro de la indemnización de daños", en: Turner, Susan; VARAs, Juan Andrés (coords.), Estudios de Derecho Civil, LexisNexis, Santiago, 2005, pp. 105-126; Corral, Hernán, Contratos y daños por incumplimiento, LegalPublishing, Santiago, 2010, pp. 155-157; ConTARDo, Juan Ignacio, "Independencia de la acción de perjuicios en sede contractual. Corte Suprema, Primera Sala (Civil), 10 de septiembre de 2013, Rol N 885-2013", Revista Chilena de Derecho Privado, 2014, N 22 , pp. 265-268.
} 
por la distinción; luego, expondremos las razones que, según la doctrina mayoritaria, avalan su rechazo; enseguida, refutaremos las mentadas razones, defendiendo su existencia en nuestro sistema civil; posteriormente, sustentaremos la excepcionalidad de la pretensión de cumplimiento por equivalencia; finalmente, presentaremos nuestras conclusiones.

\section{BASES NORMATIVAS Y CONSECUENCIAS DE LA DISTINCIÓN ENTRE CUMPLIMIENTO POR EQUIVALENCIA E INDEMNIZACIÓN DE PERJUICIOS}

Parte de la doctrina sostiene que la distinción entre cumplimiento por equivalencia e indemnización de perjuicios fluye de diversas disposiciones del Código Civil. A este efecto, se citan, entre otros, los artículos 1486 inciso primero, 1502 inciso segundo, 1504 inciso segundo, 1521, $1553 \mathrm{~N}^{\circ} 2,1555$ inciso segundo, 1672, 1678 y 2302 inciso primero. ${ }^{11}$

Buena parte de las disposiciones referidas consagrarían la perpetuatio obligationis, esto es, la subsistencia de una obligación de especie en aquellos casos en que, sin llegar a configurarse el modo de extinguir pérdida de la cosa, la ejecución de la prestación ha devenido total y definitivamente imposible. En este evento, a fin de posibilitar la subsistencia de la obligación, la especie perdida sería sustituida por su valor en dinero (aestimatio rei), que el Código Civil usualmente sindica como precio. ${ }^{12}$ En este orden de ideas, sin perjuicio de la eventual reparación de daños concurrentes, la dación de la aestimatio rei implicaría cumplimiento de la obligación, extinguiéndose esta por pago (ex artículos $1567 \mathrm{~N}^{\circ} 1$ y 1568).

Una disposición que reflejaría con claridad las implicancias de la perpetuatio obligationis es el artículo 1521. Conforme con esta, "si la cosa perece por culpa o durante la mora de uno de los codeudores solidarios, todos ellos quedan obligados solidariamente al precio, salva la acción de los codeudores contra el culpable o moroso. Pero la acción de perjuicios a que diere lugar la culpa o mora, no podrá intentarla el acreedor sino contra el deudor culpable o moroso". La subsistencia de la solidaridad respecto al precio se sustentaría en que este es el nuevo objeto de la prestación, sin que

\footnotetext{
${ }^{11}$ Baraona, cit. (n. 7), pp. 159-161; Peñailillo, cit. (n. 10), pp. 335 y 336; Bustamante, cit. (n. 10), p. 109; Corral, cit. (n. 10), pp. 155 y 156; Contardo, cit. (n. 10), pp. 266 y 267.

12 Baraona, cit. (n. 7), p. 160.
} 
el perecimiento de la cosa haya tenido el efecto de extinguir la obligación; la indemnización, por su parte, constituiría una nueva obligación, que presupone el padecimiento de un daño y que solo puede exigirse a quien pueda imputarse la perdida. ${ }^{13}$

Otra disposición que ilustraría el fundamento y alcance de la perpetuatio obligationis es el artículo 1678. Según esta, "si la cosa debida se destruye por un hecho voluntario del deudor, que inculpablemente ignoraba la obligación, se deberá solamente el precio sin otra indemnización de perjuicios". La disposición, que hace expresa alusión a la ignorancia excusable del deudor acerca de la existencia de la obligación, demostraría que el derecho para exigir la aestimatio rei no presupone que la pérdida sea culpable, sino, simplemente, que no se haya configurado el modo de extinguir "pérdida de la cosa que se debe". ${ }^{14}$ En el caso particular, la destrucción no derivaría de un hecho externo al deudor, de modo que, al no concurrir un caso fortuito, no se extinguiría la obligación.

Aunque bajo una lógica distinta a la de la perpetuatio obligationis, la distinción entre cumplimiento por equivalencia e indemnización de perjuicios estaría también reconocida por los artículos $1553 \mathrm{~N}^{\circ} 2$ y 1555 inciso segundo. Según la primera disposición, si la obligación es de hacer y el deudor está en mora, podrá pedir el acreedor, entre otras opciones y junto con la indemnización de la mora, que se le autorice para encargar a un tercero la ejecución del hecho debido a expensas del deudor. En este evento, ya sea que el deudor satisfaga voluntariamente la suma requerida o sea necesaria la realización de algunos de sus bienes, el acreedor obtendrá, si bien no un cumplimiento exacto (pues la prestación no será ejecutada por el deudor), uno por equivalencia, que dista de constituir una indemnización compensatoria. ${ }^{15}$ Por su parte, ante la contravención de una obligación de no hacer, el artículo 1555 inciso segundo dispone que "pudiendo destruirse la cosa hecha, y siendo su destrucción necesaria para el objeto que se tuvo en mira al tiempo de celebrar el contrato, será el deudor obligado a ella, o autorizado el acreedor para que la lleve a efecto a expensas del deudor". En consecuencia, la destrucción de lo hecho pasaría a constituir la nueva

\footnotetext{
${ }^{13}$ Baraona, cit. (n. 7), p. 160; Corral, cit. (n. 10), pp. 155 y 156.

${ }^{14}$ Baraona, cit. (n. 7), p. 164; Corral, cit. (n. 10), p. 156.

15 Baraona, cit. (n. 7), p. 161. La calificación de esta hipótesis como una de cumplimiento por equivalencia, enmarcada en la pretensión de cumplimiento, es compartida incluso por cierta doctrina que aboga por el realismo integrador (BAHAMONDES, cit. (n. 10), p. 615; De LA MAZA y VIDAL, cit. (n. 3), p. 374; Morales, cit. (n. 8), pp. 84, 85 y 89-91).
} 
prestación, pudiendo ser ejecutada por el propio deudor o por un tercero a sus expensas. ${ }^{16}$

A todas las disposiciones referidas se añaden los artículos $235 \mathrm{~N}^{\circ}$ 2, 438 numerales 2 y 3, y 536 del Código de Procedimiento Civil. ${ }^{17}$ Los artículos $235 \mathrm{~N}^{\circ} 2$ y $438 \mathrm{~N}^{\circ} 2$, a propósito de la ejecución de resoluciones pronunciadas por tribunales nacionales y del procedimiento ejecutivo para obligaciones de dar, disponen que, en caso de que la especie o cuerpo cierto debida no se encuentre en poder del deudor, la ejecución recaerá sobre su valor, haciéndose la avaluación por un perito nombrado por el tribunal. Por su parte, según el artículo $438 \mathrm{~N}^{\circ} 3$, si la obligación es de género determinado, la ejecución también recaerá sobre su valor, haciéndose la tasación de la misma forma que en el caso anterior. Finalmente, el artículo 536, complementando al artículo $1553 \mathrm{~N}^{\circ} 2$ del Código Civil, precisa los casos en que el acreedor puede solicitar que se le autorice para ejecutar el hecho debido por medio de un tercero y a expensas del deudor.

En suma, a la luz de las disposiciones citadas, la dación de la estimación pecuniaria del objeto de la prestación constituiría simplemente una modalidad de cumplimiento específico, sin que se requiera para su exigibilidad de la existencia de una conducta culpable. ${ }^{18}$ El derecho a exigir el mentado equivalente tendría lugar ante el evento de la perpetuatio obligationis -que no siempre supone culpa $-\mathrm{y}$ también en aquellos en que el derecho sustantivo reconoce expresamente la opción al acreedor (como ocurre en el caso del artículo $1553 \mathrm{~N}^{\circ}$ 2). Si el incumplimiento ha causado, además, algún daño, nacería una obligación ex novo (la obligación indemnizatoria), distinta conceptualmente a la incumplida. ${ }^{19}$ En este orden, el daño reparable tendría que ser necesariamente diverso al valor del objeto de la prestación, pues este valor no constituiría propiamente un perjuicio. ${ }^{20}$ Adicionalmente, la distinción entre cumplimiento por equivalencia e indemnización permitiría

\footnotetext{
${ }^{16}$ Baraona, cit. (n. 7), p. 161. En el mismo sentido, Bahamondes, cit. (n. 10), p. 615.

${ }^{17}$ Baraona, cit. (n. 7), pp. 159 y 160; PeÑaIlillo, cit. (n. 10), pp. 334 y 335.

${ }^{18}$ Baraona, cit. (n. 7), pp. 162-165; Bustamante, cit. (n. 10), pp. 117, 118, 120 y 122; Peñailillo, cit. (n. 10), p. 335; CoRral, cit. (n. 10), p. 156.

${ }^{19}$ Baraona, cit. (n. 7), p. 158; Bustamante, cit. (n. 10), pp. 117 y 119.

${ }^{20}$ Baraona, cit. (n. 7), pp. 159 y 160; Peñailillo, cit. (n. 10), p. 335; Contardo, cit. (n. 10), pp. 267 y 268. En una aproximación conceptualmente diversa, CORRAL estima que el valor de la prestación efectivamente constituiría un daño, aunque sujeto al régimen del cumplimiento específico, que prescinde de la culpa, Corral, cit. (n. 10), pp. 156 y 157. En el mismo sentido, Bustamante, cit. (n. 10), pp. 108-112.
} 
delimitar el alcance de las cauciones, las que asegurarían solamente el equivalente pecuniario, sin extenderse a la reparación de daños. ${ }^{21}$

\section{RAZONES PARA EL RECHAZO DE LA DISTINCIÓN}

A juicio de varios autores, la tesis recién expuesta presenta diversos inconvenientes prácticos, siendo, además, muy improbable que un incumplimiento no cause daños que vayan más allá del valor de la prestación. De este modo, perdería justificación práctica la imposición de la necesidad de una doble tasación (respecto de la aestimatio rei y de los daños propiamente tales). ${ }^{22}$

Ante este escenario, buena parte de la doctrina nacional ${ }^{23}$ ha procurado refutar la distinción, afirmando la insuficiencia de disposiciones de derecho sustantivo que permitan fundarla, la función resarcitoria que desempeña el cumplimiento por equivalencia y la inconveniencia de que existan dos regímenes resarcitorios con requisitos de procedencia diversos.

1. Sobre la insuficiencia de disposiciones de derecho sustantivo que permitan fundar la distinción entre cumplimiento por equivalencia e indemnización de perjuicios

Autores nacionales avezados parten por desmentir que el artículo 1672 sirva de base para sustentar que el cumplimiento por equivalencia constituye una modalidad de cumplimiento que prescinde de la culpa. De manera análoga a lo que plantea SÁnchez para el caso español, ${ }^{24}$ estos autores sostienen que el derecho del acreedor al precio de la cosa y a la indemnización de los demás daños se sustenta, justamente, en la imputabilidad de la pérdida, ${ }^{25}$ lo que sería indiciario de la existencia de un único régimen indemnizatorio, en

\footnotetext{
${ }^{21}$ BARAONA, cit. (n. 7), pp. 161 y 162.

${ }^{22}$ VATTIER, cit. (n. 9), p. 60.

${ }^{23}$ Vidal, cit. (n. 10), pp. 495 y 496; De la Maza y Vidal, cit. (n. 3), pp. 371-374; Pizarro, cit. (n. 10), pp. 299-308; BAHAMONDES, cit. (n. 10), pp. 611-614; BAHAMONDES, cit. (n. 2), pp. 170-177; CÁRDENAS y ReVeco, cit. (n. 3), pp. 295-298 y 304; Alcalde, cit. (n. 10), pp. 57 y 70.

${ }^{24}$ SÁncheZ, cit. (n. 8), p. 1747.

${ }^{25}$ Vidal, cit. (n. 10), p. 495; De la Maza y Vidal, cit. (n. 3), pp. 373 y 374; Bahamondes, cit. (n. 10), p. 614; BAHAMONDES, cit. (n. 2), p. 175.
} 
cuyo marco el precio no sería más que la avaluación de un daño. ${ }^{26}$

La unidad de régimen se vería también reflejada en el artículo 1590 , disposición que, ante deterioros culpables, faculta al acreedor para pedir indemnización de perjuicios. En esta hipótesis la reparación se referiría necesariamente al menor valor de la especie y los demás daños sufridos por el acreedor a consecuencia del incumplimiento imputable, desmintiendo que la mentada merma de valor permita solicitar, a título de cumplimiento, una suma de dinero que complete el valor de la cosa. ${ }^{27}$

El tenor del artículo 1678 también demostraría que la aestimatio rei no consiste sino en la avaluación de un daño, pues la disposición refiere que, si la especie se destruye por un hecho voluntario del deudor que inculpablemente ignoraba la obligación, "se deberá solamente el precio sin otra indemnización de perjuicios". ${ }^{28}$ En este sentido, las alusiones al precio contempladas en los artículos 1486 inciso primero, 1504 inciso segundo, 1521 y 1672, entre otros, no referirían más que una avaluación del daño sufrido en la cosa. ${ }^{29}$

En cuanto al artículo 438 del Código de Procedimiento Civil, algunos autores nacionales, en línea con el español Morales, ${ }^{30}$ sostienen que los numerales 2 y 3 contemplan hipótesis de ejecución en equivalencia, que no implican un reconocimiento sustantivo de una modalidad de cumplimiento específico, sino la consecuencia de ciertos límites previstos en el derecho procesal, que en ciertos casos y respecto de algunas obligaciones no dinerarias, impone la transformación del objeto de la prestación en una suma de dinero equivalente a su valor, sea ello por dificultades asociadas a la ejecución en naturaleza, sea por la escasa relevancia que cierta clase de obligaciones tenía al momento en que entró en vigor el Código de Procedimiento Civil. ${ }^{31}$

\footnotetext{
${ }^{26}$ Bahamondes, cit. (n. 10), p. 614.

${ }^{27}$ De la Maza y Vidal, cit. (n. 3), p. 372.

${ }^{28}$ AlCALde, cit. (n. 10), p. 70; LóPez, cit (n. 5), p. 166, nota al pie $\mathrm{N}^{\circ} 407$.

${ }^{29}$ LÓPEZ, cit. (n. 5), pp. 170 y 171.

${ }^{30}$ Morales, cit. (n. 8), pp. 90 y 91.

${ }^{31}$ Vidal, cit. (n. 10), pp. 493 y 494; De la Maza y Vidal, cit. (n. 3), p. 374; Bahamondes, cit. (n. 10), pp. 610, 616-619. Levemente distinta es, en este punto, la opinión del español SÁnCHEZ CASTRO, para quien las reglas procesales que permiten la ejecución por equivalencia, también contempladas en la Ley de Enjuiciamiento Civil española, configuran un régimen indemnizatorio especial, que prescinde de los requisitos exigidos en el Código Civil español (SÁncheZ, cit. (n. 8), pp. 1736-1740). Entre nosotros, en una línea similar, LóPEz, cit. (n. 5), p. 171.
} 
2. Sobre la función resarcitoria del interés del acreedor que desempeñaría el cumplimiento por equivalencia

Quienes abogan por un realismo integrador sostienen que, sin perjuicio de los límites establecidos por el artículo 1558 en torno a la extensión de los daños reparables, la indemnización cumpliría una doble función, a saber, restitutoria -o satisfactiva, si se prefiere- y reparatoria, comprendiendo tanto el valor de la prestación como los daños que haya causado el incumplimiento. ${ }^{32}$

En este orden de ideas, la pérdida imputable de la especie debida configuraría un daño intrínseco, ${ }^{33}$ esto es, un daño en la cosa misma, categoría que encontraría su origen en un pasaje de Paulo en el Digesto ${ }^{34}$ y que habría sido también reconocida por PoTHIER ${ }^{35}$ y alguna doctrina nacional. ${ }^{36}$ En consecuencia, el equivalente pecuniario constituiría una medida de resarcimiento que, junto a la reparación de otros daños, permitiría dejar al acreedor en la misma situación en que se encontraría de haberse cumplido la obligación en la forma acordada por las partes. ${ }^{37}$

3. Sobre la inconveniencia de la existencia de dos regímenes resarcitorios con requisitos de procedencia diversos

La construcción dogmática de la aestimatio rei como un efecto de la perpetuatio obligationis bifurca innecesariamente el resarcimiento de los intereses del acreedor en dos regímenes diversos: uno para el cumplimiento por equivalencia y otro para la indemnización. ${ }^{38}$

La integración del equivalente pecuniario en la indemnización simplificaría el régimen de remedios, evitando la necesidad de una doble avaluación. ${ }^{39}$

\footnotetext{
${ }^{32}$ López, cit. (n. 5), pp. 167-169; Bahamondes, cit. (n. 2), p. 172; Vidal, cit. (n. 10), pp. 488 y 489; AlCALDE, cit. (n. 10), pp. 57 y 58,

${ }^{33}$ Cárdenas y Reveco, cit. (n. 3), pp. 297 y 298; Alcalde, cit. (n. 10), p. 70; López, cit. (n. 5), p. 168.

${ }^{34}$ D. $19,1,21,3$.

${ }^{35}$ PотніеR, Robert, Tratado de las Obligaciones, Editorial Heliasta S.R.L., Buenos Aires, 1993, traducción de M. C. de las Cuevas, pp. 92 y 93.

${ }^{36}$ Claro, cit. (n. 1), pp. 640 y 641; Rodríguez, cit. (n. 1), p. 231

${ }^{37}$ López, cit. (n. 5), pp. 168 y 169.

${ }^{38}$ LÓPEZ, cit. (n. 5), pp. 169 y 170.

${ }^{39}$ LóPEZ, cit. (n. 5), pp. 169 y 170.
} 
A mayor abundamiento, la existencia de dos regímenes generaría inseguridad jurídica, pues la generalización de la opción por el equivalente pecuniario permitiría al acreedor encubrir una pretensión indemnizatoria bajo la apariencia de una de cumplimiento (por equivalencia), escapando de la necesidad de que concurran todas las condiciones de procedencia de la indemnización. ${ }^{40}$

\section{REFUTACIÓN DEL REALISMO INTEGRADOR}

1. Sobre la pretendida insuficiencia de disposiciones de derecho sustantivo que permitan fundar la distinción entre cumplimiento por equivalencia e indemnización de perjuicios

Los argumentos que abogan por el realismo integrador, si bien agudos y fundados, no tienen la virtud de desmentir que el Código recoge con claridad la distinción entre cumplimiento por equivalencia e indemnización de perjuicios.

Ninguno de los autores citados se hace cargo de que los artículos 1521 y 1678 efectivamente confieren al acreedor el derecho a exigir el precio de la cosa en hipótesis en que no ha habido culpa.

El solo hecho de que el supuesto contemplado en el artículo 1678 no dé lugar a "otra indemnización de perjuicios" no implica que el precio deba ser concebido automáticamente como la avaluación de un pretendido daño. El supuesto de hecho revela la inexistencia de culpa, ${ }^{41}$ circunstancia que, en el marco de nuestro sistema de responsabilidad contractual, desmiente que el precio pueda ser concebido como la avaluación de un daño. En efecto, por mucho que quiera afirmarse que el derecho al precio constituye una hipótesis de responsabilidad estricta, lo cierto es que, a la luz de un entendimiento renovado de las exigencias del caso fortuito y del tenor del

\footnotetext{
${ }^{40}$ Así lo expresa LóPEZ, cit. (n. 5), p. 172, siguiendo muy de cerca a SÁnCHEZ, cit. (n. 8), pp. 1733, 1734, 1740 y 1741. El autor español añade que resulta difícilmente justificable que, en el caso de obligaciones indivisibles, la imposibilidad sobrevenida, total y definitiva pueda, en su caso, dar lugar a la aestimatio rei, mas no ocurra así con la imposibilidad parcial o con los defectos o deterioros sufridos por la cosa, que se sujetan siempre a las reglas de la indemnización de perjuicios. SÁnchez, cit. (n. 8), p. 1746.

${ }^{41}$ Al respecto, véase Claro, Luis, Explicaciones de derecho civil chileno y comparado, Editorial Jurídica, Santiago, 2013, T. XII, p. 501. En similar sentido, Alessandri, cit. (n. 1), p. 470; MezA, cit. (n. 1), p. 227.
} 
artículo 1547 inciso tercero, buena parte de la doctrina nacional concluye que la indemnización de perjuicios requiere culpa o dolo. ${ }^{42}$

En lo que atañe al artículo 1521, la extensión de la solidaridad a la aestimatio rei en caso de perpetuatio obligationis es una prueba indiscutible de que nuestro Código distingue entre cumplimiento por equivalencia e indemnización de perjuicios. La doctrina española que aboga por el realismo integrador, que ciertamente ha influido en los autores nacionales, no ha debido sortear un obstáculo tan decidor como el referido artículo $1521 .{ }^{43}$ Por el contrario, la disposición correspectiva, esto es, el artículo 1147 del Código Civil español, establece que "todos serán responsables, para con el acreedor, del precio y de la indemnización de daños y abono de intereses, sin perjuicio de su acción contra el culpable o negligente”. Según Pantaleón Prieto, la mentada disposición desempeñaría un rol determinante para negar la distinción en el sistema español, pues se distancia de la solución clásica, que, bajo el influjo de la perpetuatio obligationis, mantiene la solidaridad respecto del precio y atribuye responsabilidad por los perjuicios solamente al deudor culpable. ${ }^{44}$ En efecto, según PothiER, que en este punto sigue a Dumoulin, el hecho, la culpa o la mora de uno de los deudores solidarios afecta a sus codeudores, ad conservandam et perpetuendam obligationem -es decir, a que no sean liberados de su obligación por la pérdida de la cosa, sino que deban pagar su precio-, mas no a la indemnización de los daños, de los que solo responde aquel que ha incurrido en el hecho, la culpa o la mora. ${ }^{45}$ De esta manera, en el sistema español existe una razón de peso para desechar la distinción, además de diversas disposiciones que integran el valor de la prestación en la indemnización. ${ }^{46}$ Además, en la regulación del Código Civil

\footnotetext{
${ }^{42} \mathrm{Al}$ respecto, para un análisis completo y desprejuiciado, LóPEZ, cit. (n. 5), pp. 173-183.

${ }^{43}$ Conviene realizar una referencia al debate español, pues, como puede comprobarse en diversas notas al pie en este trabajo, buena parte de la doctrina nacional que aboga por el realismo integrador sigue de cerca los planteamientos de algunos autores españoles. En rigor, según se expondrá, las sustantivas diferencias entre uno y otro sistema jurídico justifican tratamientos dogmáticos también sustantivamente diferenciados.

${ }^{44}$ Pantaleón, cit. (n. 8), pp. 1054 y 1055.

${ }^{45}$ Pothier, cit. (n. 36), pp. 150 y 151.

${ }^{46}$ En esta línea, el artículo $1122 \mathrm{~N}^{\circ}$ 2, a propósito de las obligaciones condicionales, señala que: "cuando las condiciones fueren puestas con el intento de suspender la eficacia de la obligación de dar, se observarán las reglas siguientes, en el caso de que la cosa mejore o se pierda o deteriore pendiente la condición: (...) 2. ${ }^{a}$ Si la cosa se perdió por culpa del deudor, éste queda obligado al resarcimiento de daños y perjuicios. Entiéndese que la cosa se pierde cuando perece, queda fuera del comercio o desaparece de modo que se ignora su existencia, o no se puede recobrar (...)”. El artículo 1135, a propósito de las obligaciones alternativas, dispone que "el acreedor tendrá derecho a la indemnización
} 
español de la pérdida de la cosa debida (artículos 1182 a 1186) no existen disposiciones análogas a los artículos 1672 y 1678 del Código de Bello. En este contexto, disposiciones como los artículos 1136 numerales 2 y $3,{ }^{47}$ $1150^{48}$ y $1185,{ }^{49}$ por muy sugerentes que sean aisladamente consideradas, parecen insuficientes para fundar la autonomía de la aestimatio rei en el sistema español.

Más allá del punto anterior, la mayoría de los autores nacionales que rechazan la distinción tampoco se pronuncian explícitamente respecto de la naturaleza de los remedios contemplados en los artículos $1553 \mathrm{~N}^{\circ} 2$ y 1555 inciso segundo del Código Civil. ${ }^{50}$ Con todo, la generalidad de la doctrina trata estos remedios con ocasión del cumplimiento específico, ${ }^{51}$ sin que a la fecha existan opiniones que opten por concederles naturaleza

de daños y perjuicios cuando por culpa del deudor hubieran desaparecido todas las cosas que alternativamente fueron objeto de la obligación, o se hubiera hecho imposible el cumplimiento de ésta. La indemnización se fijará tomando por base el valor de la última cosa que hubiese desaparecido, o el del servicio que últimamente se hubiera hecho imposible". Resulta clara la distancia que existe entre estas disposiciones y los artículos 1486 inciso primero y 1504 inciso segundo del Código de Bello.

${ }^{47}$ Artículo 1136. Cuando la elección hubiere sido expresamente atribuida al acreedor, la obligación cesará de ser alternativa desde el día en que aquélla hubiese sido notificada al deudor.

Hasta entonces las responsabilidades del deudor se regirán por las siguientes reglas:

(...) 2. ${ }^{a}$ Si la pérdida de alguna de las cosas hubiese sobrevenido por culpa del deudor, el acreedor podrá reclamar cualquiera de las que subsistan, o el precio de la que, por culpa de aquél, hubiera desaparecido.

3. ${ }^{a}$ Si todas las cosas se hubiesen perdido por culpa del deudor, la elección del acreedor recaerá sobre su precio.

Las mismas reglas se aplicarán a las obligaciones de hacer.

${ }^{48}$ Artículo 1150. La obligación indivisible mancomunada se resuelve en indemnizar daños y perjuicios desde que cualquiera de los deudores falta a su compromiso. Los deudores que hubiesen estado dispuestos a cumplir los suyos, no contribuirán a la indemnización con más cantidad que la porción correspondiente del precio de la cosa o del servicio en que consistiere la obligación.

${ }^{49}$ Artículo 1185. Cuando la deuda de cosa cierta y determinada procediere de delito o falta, no se eximirá al deudor del pago de su precio, cualquiera que hubiese sido el motivo de la pérdida, a menos que, ofrecida por él la cosa al que la debía recibir, éste se hubiese sin razón negado a aceptarla.

${ }^{50}$ La excepción es BAHAMONDES, quien, pese a ser partidaria de un realismo integrador, sugiere que la facultad que el artículo $1553 \mathrm{~N}^{\circ} 2$ confiere al acreedor de una obligación de hacer constituye una medida de ejecución que, aunque tienda a la obtención de un equivalente pecuniario, se enmarca en la pretensión de cumplimiento (BAHAMONDES, cit. (n. 10), p. 615). Se trata de la misma tesis que sustenta para el caso español Morales, cit. (n. 8), pp. 84, 85 y 89-91.

La autora nacional expone el mismo razonamiento respecto de la hipótesis contemplada en el artículo 1555 inciso segundo, destacando la remisión que el artículo 544 del Código de Procedimiento Civil realiza a las reglas que disciplinan la ejecución de las obligaciones de hacer (BAHAMONDES, cit. (n. 10), p. 615).

${ }^{51}$ Alessandri, cit. (n. 1), pp. 71-74; Claro, cit. (n. 1), pp. 613-617; Fueyo, cit. (n. 1), pp. 287, 288, 290 y 291; MeZa, cit. (n. 1), pp. 95 y 96; Ramos, cit. (n. 1), pp. 236-238; Abeliuk, cit. (n. 1), pp. 937-941; VIAL, cit. (n. 1), p. 204. 
indemnizatoria. Por lo demás, aunque estas disposiciones deban coordinarse con los artículos 536 y siguientes del Código de Procedimiento Civil, no es realmente el derecho procesal el que impone la transformación de las prestaciones para efectos de facilitar la ejecución, ${ }^{52}$ sino que es el derecho civil el que, en las dos disposiciones comentadas, reconoce la opción al acreedor. $^{53}$

2. Sobre la pretendida función resarcitoria que desempeñaría el cumplimiento por equivalencia

En el caso de obligaciones de especie, la pretendida función resarcitoria del cumplimiento por equivalencia asume como premisa que la aestimatio rei obra como una avaluación del daño experimentado por el acreedor. Este daño, denominado daño intrínseco, sería reparado mediante la dación de la aestimatio.

Supuestamente, la categoría de daño intrínseco sería reconocida por PAULO, quien en un pasaje del Digesto expresa " $(c)$ um per venditorem steterit quo minus rem tradat, omnis utilitas emptoris in aestimationem venit: quae modo circa ipsam rem consistit. Neque enim, si potuit ex vino puta negotiari, et lucrum facere, id aestimandum est, non magis quam si triticum emerit, et ob eam rem quod non sit traditum, familia ejus fame laboraverit: nam pretium tritici, non servorum fame necatorum, consequitur". ${ }^{54}$

Más allá de la referencia al precio del grano, la regla sustantiva de PAUlo consiste en que la responsabilidad del vendedor por la no entrega de la cosa se acota solo a los beneficios que estén en estrecha relación con la cosa. En otras palabras, la responsabilidad del vendedor debe supeditarse a la estimación pecuniaria del riesgo que con seguridad aquel ha asumido al momento de la celebración del contrato. ${ }^{55}$ De este modo, contrariamente a lo que en ocasiones se ha asumido, ${ }^{56}$ PAULO no se refiere tanto al daño sufrido en

\footnotetext{
${ }^{52}$ Afirmando que es el derecho procesal el que impone la referida transformación, DE LA MAZA y VIDAL, cit. (n. 3), p. 374

${ }^{53}$ Para el caso de las obligaciones de hacer, el artículo 1553 contempla tres remedios que, junto con la posibilidad de pedir indemnización moratoria, el acreedor puede ejercer a su libre arbitrio. FuEYo, cit. (n. 1), p. 228.

${ }^{54}$ D. $19,1,21,3$.

${ }^{55}$ Home, Henry, Principles of equity, Liberty Fund, Indianapolis, 2014, 3a edición, pp. 189 y 190.

${ }^{56}$ No se nos escapa que incluso Llamas, que defiende fervientemente la distinción entre cumplimiento por equivalencia e indemnización de perjuicios, ha sugerido que el pasaje de Paulo se refiere a los
} 
la cosa misma, sino, más bien, al daño que, ante el incumplimiento, resulta realmente resarcible. La finalidad de PAULO es delimitar o derechamente excluir la reparación del lucro cesante. ${ }^{57}$ Daño intrínseco, en la visión de Paulo, no es otra cosa que daño resarcible.

En la doctrina nacional, Claro, basándose en Pothier, afirma que los daños intrínsecos son los sufridos en relación con la cosa, equivaliendo a los daños directos, mientras que los extrínsecos solo son consecuencias mediatas del incumplimiento, equivaliendo a los indirectos. ${ }^{58}$ Así, más allá de que, según el mismo PotHIER, un daño extrínseco eventualmente también podría ser catalogado de directo -si es que ha sido previsible al momento de la celebración del contrato y el deudor ha asumido expresa o tácitamente su riesgo- ${ }^{59}$ tampoco es efectivo que en la obra de CLARo los daños intrínsecos sean daños que sufre la cosa misma.

Técnicamente, РотніER sugiere que los daños intrínsecos son aquellos que sufre el acreedor en relación con la cosa, no en la cosa. En sus palabras, "por lo común se reputa que las partes no han previsto más que los daños y perjuicios que resultan para el acreedor del incumplimiento de la obligación, y en relación con la cosa que es objeto de la misma, y no aquellos que la inejecución de la obligación le ha ocasionado a otros bienes. Es por esto que, en ese caso, el deudor no es reputado responsable de estos últimos, sino tan solo de aquellos sufridos en relación a la cosa que era objeto de la obligación: damni et interesse, propter ipsam rem non aditem". ${ }^{60}$

Los ejemplos de que se sirve POTHIER para ilustrar la categoría de daño intrínseco corresponden a hipótesis en que el acreedor insatisfecho ha debido celebrar una operación de reemplazo a mayor costo, o ha asumido gastos que no habría tenido que asumir de haberse cumplido la obligación en los términos pactados, o, en fin, ha pagado por la cosa un precio mayor del que le habría correspondido habida cuenta de sus defectos. ${ }^{61} \mathrm{Ni}$ siquiera

\footnotetext{
daños en la cosa. Llamas, cit. (n. 4), p. 16.

${ }^{57}$ Rodrigo, Azahara, "Evolución histórica de la figura del lucro cesante", Anuario da Facultade de Dereito da Universidade da Coruña, 2003, № 7, p. 647.

${ }^{58}$ Claro, cit. (n. 1), pp. 640 y 641.

${ }^{59}$ Pothier, cit. (n. 36), p. 93.

${ }^{60}$ Pothier, cit. (n. 36), p. 92.

${ }^{61}$ Pothier, cit. (n. 36), pp. 92-94. En el caso de la venta de un caballo que no es entregado oportunamente, el daño intrínseco está referido al mayor precio pagado por el comprador para adquirir otro caballo de la misma calidad. En la hipótesis del alquiler de una casa que es reivindicada por el verdadero dueño, el daño intrínseco sufrido por el inquilino está representado por los gastos de mudanza y por el
} 
el último caso trata realmente de un daño sufrido por la cosa (como ocurriría, por ejemplo, si la cosa, antes de ser entregada al acreedor, hubiese sufrido algún deterioro imputable al deudor), sino de una hipótesis en que la cosa vendida, por sus defectos (acaso coetáneos a la venta), no sirve para satisfacer completamente el interés del comprador. ${ }^{62}$ En suma, los ejemplos solo ilustran que, sin necesidad de una asunción tácita o expresa de un riesgo concreto, ciertos daños deben ser necesariamente reparados por el deudor, lo que ocurre cuando el incumplimiento afecta aquella medida de interés que indiscutible y previsiblemente alberga el acreedor en el cumplimiento de la obligación. No se trata de hipótesis de daño en la cosa, sino en relación con ella. ${ }^{63}$

A mayor abundamiento, PотніER adscribe con toda claridad a la doctrina de la perpetuatio obligationis. ${ }^{64}$ Según él, "si la pérdida de la cosa debida ocurre por el hecho del deudor, es evidente que la obligación no debe por esto quedar extinguida, y que debe convertirse en la obligación del precio de esta cosa; pues el deudor no puede por su hecho liberarse de su obligación, y hacer perder a su acreedor su crédito". ${ }^{65}$ Además, el jurista aclara que el precio de la cosa no solo resulta exigible en contra del deudor y sus herederos, sino también respecto de todos aquellos que hayan accedido a la obligación; ${ }^{66}$ no obstante, esta afectación no compromete a los garantes por los daños concurrentes, pues la culpa o mora del deudor no puede producir el efecto de aumentar la obligación de los garantes (non

aumento en el valor de la renta que tenga que pagar a un tercero durante el período para el cual estaba presupuestado el contrato incumplido. En el caso de la venta de cierto número de piezas de madera defectuosas, el daño intrínseco está representado por el precio que el comprador ha pagado de más "al comprar por bueno lo que era defectuoso".

${ }^{62}$ PотніER dice "he aquí otro ejemplo de nuestra distinción. Una persona me ha vendido un cierto número de piezas de madera, de la que me he servido para apuntalar mi casa, que se arruina, por defecto de la mala calidad de los maderos que estaban podridos. Si el vendedor no era hombre entendido en el asunto, es decir, que no era de su oficio el conocer la calidad de los maderos, de los que ignoraba sus defectos, los daños y perjuicios que resulten del hecho de que los maderos que él me vendiera fueran defectuosos, no consistirán más que en una deducción sobre el precio de lo que yo he pagado de más, al comprar por bueno lo que era defectuoso" (PотніER, cit. (n. 36), p. 94).

${ }^{63}$ A nuestro juicio, Llamas no repara mayormente en las ilustraciones de Pothier. Según él, los damni et interesse, propter ipsam rem non habitam de los que habla Pothier se refieren a daños en la cosa. Llamas, cit. (n. 4), p. 16.

${ }^{64}$ Reconociendo también este aspecto en la obra de Pothier, PeÑaIlillo, cit. (n. 10), p. 336.

${ }^{65}$ Pothier, cit. (n. 36), p. 414.

${ }^{66}$ Pothier, cit. (n. 36), pp. 415 y 416. 
nocet ad augendam obligationem). ${ }^{67}$

A la luz de las consideraciones precedentes y de la recepción del pensamiento de PothiER en diversas disposiciones del Código Civil (los artículos 1486 inciso primero, 1502 inciso segundo, 1504 inciso segundo, 1521,1672 , 1678, entre otros), resulta equivocado sostener que la destrucción de una especie implique en nuestro sistema un daño intrínseco. El evento de la perpetuatio obligationis no implica, por sí solo, una merma en el patrimonio del acreedor, pues su crédito, a la luz del artículo 1672 y las disposiciones referidas, mantiene incólume su valor. En tal evento, el objeto de la prestación pasa a ser el precio de la especie perdida, pudiendo el acreedor perseguir la ejecución de su crédito en todos los bienes muebles e inmuebles del deudor, sean presentes o futuros, salvo los no embargables. ${ }^{68}$

A lo sumo, si acaso se insiste en la utilización de la categoría, podría plantearse una hipótesis de daño intrínseco — en el impropio sentido que acuña la doctrina que aboga por el realismo integrador - en aquellos casos en que la especie debida, antes de ser entregada al acreedor, sufre deterioros. En tal evento, si los deterioros provienen de hecho o culpa del deudor o de las personas por quienes este es responsable, el acreedor podrá pedir indemnización de perjuicios (ex artículo 1590). La diferencia de tratamiento entre este caso y el de la perpetuatio obligationis se sustenta en que, una vez entregada la especie, los deterioros efectivamente implican una merma en el patrimonio del acreedor, pues la cosa, en tal estado, no logra satisfacer enteramente su interés; en cambio, cuando la entrega no se ha producido y la especie se pierde por hecho o culpa del deudor o durante su mora, la perpetuatio obligationis hace subsistir incólume el valor del crédito, de modo que el acreedor pueda, mediante el equivalente pecuniario, celebrar una operación de reemplazo y satisfacer la medida de su interés que no esté frustrada, y todo ello sin perjuicio de su derecho a exigir la reparación de los daños concurrenciales.

En suma, tal como sostuvieran juristas tan insignes como WINDSCHEID y ENNECERUS, la dación de la aestimatio rei no satisface siquiera parcialmente el interés que el acreedor alberga en la ejecución de la prestación, pues este interés, que es un interesse o pretium singulare, no se refiere al valor que la

\footnotetext{
${ }^{67}$ Pothier, cit. (n. 36), p. 416. A propósito de la extensión de la solidaridad al precio y no a los daños. Pothier, cit. (n. 36), pp. 150 y 151.

${ }^{68}$ En sentido similar, BARAONA sugiere que el valor de la prestación no puede concebirse ni como daño emergente ni como lucro cesante. BARAONA, cit. (n. 7), pp. 157 y 158. Véase también Llamas, cit. (n. 4), p. 19.
} 
cosa tiene en el mercado (pretium commune), sino al valor de la expectativa que el acreedor, conforme con el contrato, desea satisfacer con la cosa. ${ }^{69} \mathrm{De}$ esta manera, mal puede decirse que la dación del equivalente pecuniario desempeña una función resarcitoria del id quod interest.

3. Sobre la pretendida inconveniencia de la existencia de dos regímenes resarcitorios con requisitos de procedencia diversos

La cuestión de la (in)conveniencia de dos regímenes resarcitorios, además de asumir la discutible premisa de que el cumplimiento por equivalencia desempeña una función resarcitoria, es, esencialmente, una cuestión de lege ferenda. Así, si acaso realmente resultase inconveniente mantener un régimen diferenciado para el cumplimiento por equivalencia, ello a lo sumo podría servir como un antecedente para una eventual reforma legal, mas no como un argumento que dé mayor peso a una interpretación que, pretendiendo precisar la disciplina legal, desvirtúa el sentido de disposiciones plenamente vigentes.

Por lo demás, ni siquiera desde una perspectiva de lege ferenda resulta claro que la diferenciación de regímenes resulte inconveniente. Si bien la distinción entre cumplimiento por equivalencia e indemnización de perjuicios impone la necesidad de una doble avaluación, está lejos de comportar inseguridad jurídica.

Por un lado, salvo que se pretenda generalizar la opción por el equivalente pecuniario, las hipótesis en que esta resulta procedente están reconocidas por el propio sistema jurídico, de modo que, si ello incomoda al deudor, no es realmente por falta de certeza. Por el otro, la doctrina que aboga por la distinción permite delimitar la responsabilidad patrimonial de los terceros que se han obligado como garantes de la ejecución de una determinada prestación. En efecto, en el caso de que la obligación asegurada no sea de dinero, resultaría desproporcionado que el acreedor pueda perseguir en el patrimonio del fiador o en la cosa hipotecada o prendada la indemnización de todos los perjuicios resultantes del incumplimiento; en rigor, la única solución razonable, consistente y que otorga certeza

\footnotetext{
${ }^{69}$ WindscheID, Bernhard, Diritto delle Pandette, Editorial Utet, Torino, 1904, Vol. II, traducción al italiano de Carlo Fadda y Paolo Bensa, §257; EnNECCERus, Ludwig, "Derecho de Obligaciones, vol. 1", en: Enneccerus, Ludwig, KIPP, Theodor y WolfF, Martin, Tratado de Derecho Civil, Tomo II, Bosch, Barcelona, 1933, traducción y notas de Blas Pérez González y José Alguer, pp. 61 y 62; citados ambos en Llamas, cit. (n. 4), pp. 14 y 15.
} 
jurídica es que la responsabilidad patrimonial del tercero garante se extienda únicamente al equivalente pecuniario. ${ }^{70}$

Adicionalmente, sinoserealizaraunadistinciónclaraentrecumplimiento por equivalencia e indemnización de perjuicios, la responsabilidad patrimonial de los terceros garantes, en casos de imposibilidad sobrevenida imputable al deudor, podría tener dos destinos muy poco razonables. Por un lado, si, junto con la falta de distinción, la indemnización no fuera concebida como una obligación ex novo -sino como la misma obligación con un nuevo objeto-, la responsabilidad patrimonial de los terceros garantes podría extenderse, en caso de que haya dolo, a la reparación de daños imprevisibles (ex artículo 1558), lo que resulta desproporcionado y podría exceder con creces el valor del crédito insatisfecho. Por el otro lado, si, junto con la falta de distinción, la indemnización sí fuera concebida como una obligación ex novo -en la que se integra el valor pecuniario de la prestación-, entonces la responsabilidad patrimonial del tercero garante podría esfumarse, pues la obligación asegurada no tendría ya un valor propio.

Lamentablemente, el realismo integrador no presenta una solución razonable para este punto.

En otro punto, si, como hace alguna doctrina, se asume que la indemnización de los perjuicios causados por el incumplimiento constituye, ante todo, una nueva obligación, ${ }^{71}$ no resulta consistente afirmar que esta se extiende tanto al valor de la prestación como a la reparación de los daños concurrentes. Si así fuese -como el realismo integrador postula-, se generaría el paradójico resultado de que, una vez pagada la indemnización, el acreedor, pese a recibir el valor del objeto de la prestación, estaría igualmente habilitado para solicitar el cumplimiento de la obligación incumplida, pues esta, mientras no se haya configurado alguno de los modos de extinguir previstos en la ley, mantendría su eficacia. Ciertamente, si se desea evitar este enriquecimiento injusto -que sí comporta inseguridad jurídica-, resulta más consistente solucionar el problema del destino de la

\footnotetext{
${ }^{70}$ BARAONA, cit. (n. 7), pp. 161 y 162.

${ }^{71}$ Pese a abogar por un realismo integrador, asumen que la obligación indemnizatoria es una obligación ex novo, BARros, Enrique, "La diferencia entre "estar obligado" y "ser responsable"”, en: Corral, H., Rodríguez, M. Sara (coords.), Estudios de Derecho Civil II, LexisNexis, Santiago, 2007, pp. 727 y 728; CÁrdenas y ReVECo, cit. (n. 3), pp. 380-382. Desde la otra vereda, sustentando también el carácter de obligación ex novo pero bajo la consistente premisa de que el equivalente pecuniario tiene autonomía respecto de la indemnización, BARAONA, cit. (n. 7), p. 158; Bustamante, cit. (n. 10), pp. 117 y 119.
} 
obligación incumplida ${ }^{72}$ asumiendo que la dación del equivalente pecuniario constituye una modalidad de cumplimiento. ${ }^{73}$ De seguirse este camino, la dación del equivalente pecuniario importaría la extinción, por pago, de la obligación incumplida, solución que otorga bastante certeza jurídica.

A mayor abundamiento, la tesis aquí defendida refuerza que la indemnización de perjuicios, en cuanto obligación ex novo, puede pedirse de manera principal y autónoma. En efecto, separada la indemnización de perjuicios del cumplimiento por equivalencia, ya no resulta consistente la objeción de que avalar la autonomía de aquella implicaría admitir, sin base normativa para ello, que la obligación incumplida, incluso en caso de que sea de dar, tiene un objeto alternativo. ${ }^{74}$ Como veremos, esta objeción solo puede plantearse respecto del cumplimiento por equivalencia, que, en tanto implica la dación del equivalente pecuniario de la prestación incumplida, efectivamente puede concebirse como un objeto alternativo.

\footnotetext{
${ }^{72}$ Según CÁrdenas y Reveco, "la solución a esta problemática pasa por esbozar como principio, que, una vez que el acreedor solicita como indemnización el interés económico máximo del contrato, la indemnización que se otorgue en base a dicho interés debiese extinguir el contrato", CÁRDENAS y REVECO, cit. (n. 3), p. 393. En otros términos, Carrasco sostiene que, si la indemnización satisface el completo interés del acreedor en la prestación, tal indemnización obra como subrogado o sustituto de la prestación originaria, lo que no obsta a la posibilidad de que vaya más allá del valor de la prestación, CARRASCO, Ángel, "Artículo 1101 CC", en: Albaladejo, M. (Dir.), Comentarios al Código Civil y Compilaciones Forales, Editorial Revista de Derecho Privado-Editoriales de Derecho Reunidas, Madrid, 1989, T. XV, Vol. 1, p. 408. Entre nosotros, en el mismo sentido, AlCAlde, cit. (n. 10), pp. 57 y 58.

Desde una perspectiva diversa, que tampoco compartimos, hay quienes, en contra de la autonomía de la indemnización, sostienen que esta, en su vertiente compensatoria, solo puede pedirse de la mano de la resolución, pues solo así se extinguiría la obligación incumplida, cobrando justificación que el acreedor reciba, a título de indemnización compensatoria, una suma de dinero que supla el valor de la prestación. En este sentido, Vial, cit. (n. 1), pp. 208 y 209; Polit, Joaquín, “Algunas reflexiones sobre la indemnización de perjuicios como remedio autónomo frente al incumplimiento de las obligaciones de dar una especie o cuerpo cierto, en particular a la luz del caso "Zorín S.A. con Compañía Siderúrgica Huachipato", en: BARRíA, Manuel (Coord.), Estudios de Derecho Civil XI. Jornadas Nacionales de Derecho Civil Concepción, Thomson Reuters, Santiago, 2016; pp. 765-771, Alcalde, cit. (n. 1), pp. 474 y 475).

${ }^{73}$ Cárdenas y Reveco, pese a rechazar la tesis de que la dación de la aestimatio rei constituya una modalidad de cumplimiento específico, sostienen que "en nuestro sistema, nos parece que la extinción de la obligación cuando se concede una indemnización autónoma guarda más similitud con los efectos del supuesto de cumplimiento que con el de resolución de contrato". CÁrdenas y Reveco, cit. (n. 3), p. 394.

${ }^{74}$ Oponiendo esta objeción, por ejemplo, Alessandri, cit. (n. 1), p. 76; FueYo, cit. (n. 1), p. 348.
} 


\section{EXCEPCIONALIDAD DEL CUMPLIMIENTO POR EQUIVALENCIA}

La función del cumplimiento por equivalencia como modalidad de cumplimiento específico está en armonía con la tesis de que, más allá de la naturaleza del interés del acreedor, la prestación ha de tener siempre un contenido pecuniario, pues solo de esta manera puede exigirse su cumplimiento compulsivo, tornando operativo el derecho establecido en el artículo 2465 del Código Civil. ${ }^{75}$

Ahora bien, el reconocimiento de que el objeto de la prestación sea susceptible de apreciación pecuniaria no implica que el acreedor tenga un derecho alternativo para exigir el cumplimiento in natura o en equivalencia. En este sentido, el derecho que el artículo 2465 concede al acreedor ha de coordinarse con las demás disposiciones del Código Civil y con algunas particulares del Código de Procedimiento Civil.

De ahí que, tratándose de obligaciones de especie o cuerpo cierto, la pretensión de cumplimiento por equivalencia, a diferencia de la indemnización de perjuicios, ${ }^{76}$ ha de ser siempre subsidiaria, pues la alternatividad es excepcional y requiere una fuente que en este caso no existe, siendo indispensable que se haya configurado el evento de la perpetuatio obligationis. ${ }^{77}$ Dicho de otro modo, mientras no exista pérdida, el acreedor solo puede exigir el cumplimiento en naturaleza, sin perjuicio de la eventual transformación de la especie en un equivalente pecuniario por aplicación del artículo $438 \mathrm{~N}^{\circ} 2$ del Código de Procedimiento Civil. Por lo demás, ocurrido el evento de la perpetuatio obligationis, se produce la sustitución

\footnotetext{
${ }^{75}$ Fueyo, cit. (n. 1), pp. 44 y 45; Baraona, cit. (n. 7), p. 162.

${ }^{76}$ Actualmente no debiesen subsistir dudas acerca de la autonomía del remedio indemnizatorio en relación con el cumplimiento específico y la resolución. Al respecto, LóPEZ, cit. (n. 5), pp. 279-328; CÁrdenas y Reveco, cit. (n. 3), pp. 382-395; De la Maza y Vidal, cit. (n. 3), pp. 723-739. En contra, algunos autores sostienen que la indemnización compensatoria solo puede pedirse de la mano de la resolución, pues solo así se extinguiría la obligación incumplida, cobrando justificación que el acreedor reciba, a título de indemnización compensatoria, una suma de dinero que supla el valor de la prestación. En este sentido, Vial, cit. (n. 1), pp. 208 y 209, Polit, cit (n. 65), pp. 765-771, Alcalde, cit. (n. 1), pp. 474 y 475 . El problema de esta tesis es que, declarada la resolución, el contratante que haya cumplido con su prestación tiene derecho a que se le restituya lo entregado, de manera que, si a ello se acompaña una indemnización que suple el valor de la prestación incumplida, el resultado sería que un evidente enriquecimiento injustificado.

${ }^{77}$ Llamas, cit. (n. 8), pp. 249-250; SÁnchez, cit. (n. 8), pp. 1742 y 1743. Cabe añadir, no obstante, que, a juicio de estos autores, para que se pueda tener por configurada la perpetuatio obligationis basta con que la prestación originaria se haya tornado inidónea para satisfacer el interés del acreedor. LLAMAs, cit. (n. 8), p. 315; SÁnchez, cit. (n. 8), p. 1747. En Chile, en el mismo sentido, Bustamante, cit. (n. 10), pp. 106, 117, 120 y 122; PeÑaIlillo, cit. (n. 10), p. 335.
} 
de la especie perecida por la aestimatio rei, por lo que el objeto sigue siendo único.

En el caso de obligaciones de género, compartimos con BAHAMONDES que la transformación de la prestación en la dación de su equivalente pecuniario (ex artículo $438 \mathrm{~N}^{\circ} 3$ del Código de Procedimiento Civil) no es una opción reconocida al acreedor, sino el efecto de una limitación procesal, fundada en la escasa relevancia que se asignaba a esta clase de obligaciones a la época de dictación del Código de Procedimiento Civil. ${ }^{78}$

Distinto es el caso de las obligaciones de hacer, pues, sin necesidad de que se configure una imposibilidad sobrevenida no extintiva, el artículo $1553 \mathrm{~N}^{\circ} 2$ del Código Civil permite al acreedor optar por una modalidad de cumplimiento por equivalencia; de esta manera, existe base suficiente para sostener que en nuestro sistema jurídico las obligaciones de hacer que impliquen la prestación de un servicio no personalísimo o la ejecución de una obra material no personalísima son alternativas, correspondiendo la elección al acreedor. ${ }^{79}$

Lo mismo ocurre respecto de la obligación de destruir lo hecho ante la contravención de una obligación de no hacer: atendida la remisión que el artículo 544 del Código de Procedimiento Civil realiza a las reglas que disciplinan la ejecución de las obligaciones de hacer, también existe un objeto alternativo, aunque es necesario que se configure alguno de los supuestos del artículo 536 del referido Código.

Así las cosas, no podemos compartir con VIDAL que, configurado un caso fortuito que impida temporalmente el cumplimiento de la obligación, el acreedor esté habilitado para pedir el valor de la prestación, mas no a título de cumplimiento por equivalencia, sino de indemnización de perjuicios. El autor sugiere que la exoneración de responsabilidad causada por un caso fortuito se acota a los denominados daños extrínsecos y que, en este sentido, el artículo 1558 inciso segundo, en cuanto dispone que la mora causada por caso fortuito no da derecho a indemnización, se refiere únicamente a los daños que van más allá del valor de la prestación. ${ }^{80}$ En nuestra opinión, tal proceder encubriría una pretensión de cumplimiento por equivalencia bajo la apariencia de una pretensión indemnizatoria, aproximación que implica atribuir al deudor una obligación alternativa sin base normativa para ello.

\footnotetext{
${ }^{78}$ Bahamondes, cit. (n. 10), pp. 617 y 618.

${ }^{79}$ En un sentido afín para el derecho español, SÁNCHEZ, cit. (n. 8), p. 1743.

${ }^{80}$ VIDAL, cit. (n. 10), p. 499.
} 


\section{CONCLUSIONES}

La doctrina nacional que aboga por el realismo integrador no ha podido desmentir que diversas disposiciones del Código Civil chileno distinguen entre cumplimiento por equivalencia e indemnización de perjuicios. En lo que atañe a las obligaciones de especie, la regla contenida en el artículo 1521 del Código Civil, que proviene de Dumoulin y es reconocida por Pothier, implica un reconocimiento claro y sustantivo de la distinción, sustentado en la figura de la perpetuatio obligationis y en la aestimatio rei como subrogado real del objeto de la prestación.

En nuestro sistema jurídico, el cumplimiento por equivalencia no desempeña realmente una función resarcitoria del interés del acreedor. En lo que atañe a obligaciones de especie, y a la luz del pensamiento de PothiER - plasmado en diversas disposiciones de nuestro Código Civil-, la sustitución de la especie destruida por su precio no implica una avaluación de un daño intrínseco, sino el efecto de la perpetuatio obligationis, que apareja una subrogación real del objeto de la prestación. Por lo demás, la categoría de daño intrínseco no dice relación con un daño experimentado por la especie debida, sino con un daño que, sin necesidad de asunción expresa o tácita del riesgo, da lugar necesariamente a responsabilidad, por afectar la medida de interés que indiscutible y previsiblemente el acreedor alberga en el cumplimiento de la obligación. A mayor abundamiento, y sin perjuicio de la responsabilidad que pueda surgir para el deudor por los daños concurrentes, el automatismo con que opera la sustitución de la especie por su precio impide predicar la existencia de una merma en el crédito: su valor se mantiene incólume, siendo impropio predicar que la sola destrucción de la cosa configura daño emergente (pues no hay disminución actual y efectiva del patrimonio del acreedor) o lucro cesante (pues el acreedor, mediante la dación de la aestimatio rei, podrá celebrar una operación de reemplazo y obtener la cosa de manos de un tercero).

Contrariamente a lo que sostienen aquellos que abogan por el realismo integrador, la distinción entre cumplimiento por equivalencia e indemnización de perjuicios otorga mayor certeza en cuanto al destino de la obligación incumplida -que se extingue con el cumplimiento por equivalencia-, en cuanto a la responsabilidad de los garantes -que se extiende únicamente al equivalente pecuniario de la prestación- y en cuanto a la autonomía de la pretensión indemnizatoria. Por lo demás, la distinción dota de un sentido claro y preciso al artículo 2465. 
Con todo, por regla general, el acreedor solo está facultado para pedir el equivalente pecuniario cuando la prestación se ha hecho total y definitivamente imposible por causa imputable al deudor. Por excepción, la libre opción por el cumplimiento por equivalencia está expresamente reconocida a propósito de obligaciones de hacer que impliquen la prestación de un servicio no personalísimo o la ejecución de una obra material no personalísima (ex artículo $1553 \mathrm{~N}^{\circ} 2$ ). Técnicamente, estas obligaciones tienen un objeto alternativo, correspondiendo la elección al acreedor. Lo mismo ocurre respecto de la obligación de destruir lo hecho prevista por el artículo 1555 inciso segundo para el caso en que se contravenga una obligación de no hacer, pues el artículo 544 del Código de Procedimiento Civil se remite a las reglas que disciplinan la ejecución de las obligaciones de hacer y, entre estas, el artículo 536 del mismo Código contempla hipótesis que permitirían solicitar al acreedor que se le autorice a llevar a cabo la destrucción por medio de un tercero y a expensas del deudor.

\section{BIBLIOGRAFÍA CITADA}

\section{a) Doctrina}

Abeliuk, René, Las obligaciones, Thomson Reuters, Santiago, 2014, 6 edición actualizada, T. II.

Alcalde, Enrique, La responsabilidad contractual. Causa y efectos de los contratos y sus obligaciones, Ediciones UC, Santiago, 2018.

AlCALDE, Jaime, "La reaparición de la cosa perdida y la facultad del acreedor para reclamarla", Revista de Derecho P. Universidad Católica de Valparaíso, 2012, XXXVIII, pp. 39-76.

Alessandri, Arturo, Teoría de las obligaciones, Editorial Jurídica EdiarConosur Ltda, Santiago, 1988

BAHAMONDES, Claudia, "El procedimiento de ejecución forzada de las obligaciones y la aestimatio rei", en: Vidal, A. (Dir.); SEverín, G. (Ed.), Estudios de Derecho de Contratos. En homenaje a Antonio Manuel Morales Moreno, Thomson Reuters, Santiago, 2018, pp. 601-619.

Bahamondes, Claudia, El cumplimiento especifico de los contratos, Der Ediciones, Santiago, 2018.

BARAONA, Jorge, "Responsabilidad contractual y factores de imputación de daños: apuntes para una relectura en clave objetiva", Revista Chilena de Derecho, 1997, Vol. 24, N 1, pp. 151-177.

BARros, Enrique, "La diferencia entre "estar obligado" y "ser responsable"”, 
en: Corral, H.; Rodríguez, M. Sara (Coords.), Estudios de Derecho Civil II, LexisNexis, Santiago, 2007, pp. 721-752.

Bustamante, Luis, "Autonomía del equivalente pecuniario o su integración dentro de la indemnización de daños", en: Turner, S.; VAras, J. A. (Coords.), Estudios de Derecho Civil, LexisNexis, Santiago, 2005, pp. 105-126.

Cárdenas, Hugo; Reveco, Ricardo, Remedios contractuales. Cláusulas, acciones y otros mecanismos de tutela del crédito, Thomson Reuters, Santiago, 2018.

Carrasco, Ángel, "Artículo 1101 CC", en: Albaladejo, M. (Dir.), Comentarios al Código Civil y Compilaciones Forales, Editorial Revista de Derecho Privado-Editoriales de Derecho Reunidas, Madrid, 1989, T. XV, Vol. 1, pp. 374-444.

Claro, Luis, Explicaciones de derecho civil chileno y comparado, Editorial Jurídica, Santiago, 2013, T. XI.

Claro, Luis, Explicaciones de derecho civil chileno y comparado, Editorial Jurídica, Santiago, 2013, T. XIII.

ContARDO, Juan Ignacio, "Independencia de la acción de perjuicios en sede contractual. Corte Suprema, Primera Sala (Civil), 10 de septiembre de 2013, Rol N 885-2013", Revista Chilena de Derecho Privado, 2014, № 22, pp. 261-269.

Corral, Hernán, Contratos y daños por incumplimiento, LegalPublishing, Santiago, 2010.

De la Maza, Íñigo; Vidal, Álvaro, Cuestiones de Derecho de Contratos. Formación, incumplimiento y remedios. Doctrina y jurisprudencia, Thomson Reuters, Santiago, 2018.

Díez-PICAzo, Luis, Fundamentos del derecho civil patrimonial, volumen II, Las relaciones obligatorias, Civitas Thomson Reuters, Pamplona, 2008, 6 a edición.

EnNeCCerus, Ludwig, "Derecho de Obligaciones, Vol. 1", en: EnNeCcerus, Ludwig, KIPP, Theodor y Wolff, Martin, Tratado de Derecho Civil, Tomo II, Bosch, Barcelona, 1933, traducción y notas de Blas Pérez González y José Alguer. JoRdAno, Francisco, La responsabilidad contractual, Civitas, Madrid, 1987.

Fueyo, Fernando, Cumplimiento e incumplimiento de las obligaciones, Editorial Jurídica, Santiago, 2004, $3^{\mathrm{a}}$ edición actualizada por el Profesor Gonzalo Figueroa Yáñez.

Gatica, Sergio, Aspectos de la indemnización de perjuicios por incumplimiento de contrato, Editorial Jurídica, Santiago, 1958.

GómEz, Fernando, "El incumplimiento contractual en derecho español", Revista para el Análisis del Derecho, 2007, N³, pp. 1-49.

Home, Henry, Principles of equity, Liberty Fund, Indianapolis, 2014, 3a edición.

IHERING, Rudolf, "Del interés en los contratos y de la supuesta necesidad del valor patrimonial de las prestaciones obligatorias", en: IHERING, Rudolf, Tres 
Estudios Jurídicos, Editorial Atalaya, Buenos Aires, 1947, traducción de Adolfo González Posada.

Llamas, Eugenio, Cumplimiento por equivalente y resarcimiento del daño al acreedor, Editorial Trivium, Madrid, 1999.

Llamas, Eugenio, "Tipología de los intereses del acreedor e instrumentos para su satisfacción", Revista de la Asociación Española de Abogados Especializados en Responsabilidad Civil y Seguro, 2013, No 45, pp. 9-24.

LóPEz, Patricia, La autonomía de la indemnización de daños por incumplimiento de un contrato bilateral en el Código Civil chileno, Legal Publishing Chile, Santiago, 2015.

Meza, Ramón, De las Obligaciones, Editorial Jurídica, Santiago, 2007, 10ª edición actualizada.

Morales, Antonio, "Evolución del concepto de obligación en derecho español", en: Morales, Antonio, La modernización del derecho de obligaciones, Thomson-Civitas, Cizur Menor, 2006, pp. 17-54

Morales, Antonio, "Pretensión de cumplimiento y pretensión indemnizatoria", en: Morales, Antonio, La modernización del derecho de obligaciones, Thomson-Civitas, Cizur Menor, 2006, pp. 55-92.

Pantaleón, Fernando, "Las nuevas bases de la responsabilidad contractual", Anuario de Derecho Civil, 1993, 4, XLVI, pp. 1019-1091.

Peñallillo, Daniel, "Responsabilidad contractual objetiva", en: Pizarro, Carlos (coord.), Estudios de Derecho Civil IV, Legal Publishing, Santiago, 2009, pp. 331-346.

Pizarro, Carlos, "La responsabilidad contractual en el derecho chileno: función y autonomía”, en: Pizarro, Carlos; Vidal, Álvaro, Incumplimiento contractual, resolución e indemnización de daños, Bogotá, Universidad del Rosario, Bogotá, 2010, pp. 299-312.

Polit, Joaquín, "Algunas reflexiones sobre la indemnización de perjuicios como remedio autónomo frente al incumplimiento de las obligaciones de dar una especie o cuerpo cierto, en particular a la luz del caso 'Zorín S.A. con Compañía Siderúrgica Huachipato', en: BARRíA, Manuel (Coord.), Estudios de Derecho Civil XI. Jornadas Nacionales de Derecho Civil de Concepción, Thomson Reuters, Santiago, 2016, pp. 759-772.

PothiER, Robert, Tratado de las Obligaciones, Editorial Heliasta S.R.L., Buenos Aires, 1993, traducción de M. C. de las Cuevas.

Puig, José, "Comentario del traductor a la obra", en: Fuller, Lon y Perdue, William, Indemnización de los daños contractuales y protección de la confianza, Bosch, Barcelona, 1957, pp. 143-182.

Ramos, René, De las Obligaciones, LegalPublishing Chile, Santiago, 2008, $3^{\mathrm{a}}$ edición revisada y corregida.

Rodrigo, Azahara, "Evolución histórica de la figura del lucro cesante", 
Anuario da Facultade de Dereito da Universidade da Coruña, 2003, Nº 7, pp. 641-652.

Rodríguez, Pablo, Responsabilidad contractual, Editorial Jurídica, Santiago, 2003.

Ruz, Gonzalo, Explicaciones de Derecho Civil. Obligaciones, Legal Publishing Chile, Santiago, 2011.

SÁNCHEZ, Juan David, "El cumplimiento por equivalente: ¿un modo de evitar los requisitos imprescindibles en toda pretensión indemnizatoria?", Anuario de Derecho Civil, 2010, N 63, 4, pp. 1726-1787.

VATTIER, Carlos, "Notas sobre el incumplimiento y la responsabilidad contractual", Revista electrónica del Departamento de Derecho de la Universidad de La Rioja, 2005, Nº. 3, pp. 57-68.

Vial, Víctor, Manual del Derecho de las Obligaciones en el Código Civil chileno, Editorial Biblioteca Americana (Universidad Andrés Bello), Santiago, 2003.

VIDAL, Álvaro, “¿Cumplimiento en equivalencia o indemnización de daños?", en: Corral, H.; Manterola, P. (eds.), Estudios de Derecho Civil XII, Ponencias presentadas en las XIX jornadas nacionales de Derecho Civil, 6 y 7 de octubre de 2016, Maitencillo, Thomson Reuters, Santiago, 2017, pp. 485-500.

WindscheID, Bernhard, Diritto delle Pandette, Editorial Utet, Torino, 1904, Vol. II, traducción al italiano de Carlo Fadda y Paolo Bensa.

\section{b) Jurisprudencia}

Corte Suprema, 17 de abril de 2008, Rol N²97-2007.

Corte Suprema, 30 de marzo de 2009, Rol N 6779-2007.

Corte Suprema, 7 de septiembre de 2010, Rol N 1089-2009.

Corte Suprema, 25 de julio de 2011, Rol N 3929-2010.

Corte Suprema, 2 de octubre de 2013, Rol N 8607-2012.

Corte Suprema, 14 de noviembre de 2016, Rol N ${ }^{\circ}$ 5746-2016.

Corte Suprema, 30 de enero de 2020, Rol No 8596-2018. 